\title{
De generaciones a escuelas: una nueva forma de concebir los derechos humanos ${ }^{1}$
}

\section{From generations to schools: a new way of conceiving human rights}

\author{
José Ignacio Torres Justiniani²
}

\section{Resumen}

El presente artículo analiza las ventajas de transitar de una concepción de generaciones de derechos humanos a una de escuelas de derechos humanos. La clasificación de generaciones se muestra insuficiente y desfasada y no da cabal respuesta a los retos de los derechos humanos en la actualidad, por tanto, se presenta en esta investigación la posibilidad de abandonar esta clasificación y transitar a una con base en las escuelas de derechos, la cual posee más y mejores elementos para comprender los derechos humanos en el siglo XXI.

Palabras clave: Derechos Humanos; Teoría de Generaciones; Escuelas de Derechos Humanos; Universalidad.
TThis article presents the analysis of the advantages of moving from a conception of human rights generation to a conception of human rights schools. The classification of generations is insufficient and out of date, it does not fully respond to the challenges of human rights nowadays. Therefore, this work presents the possibility of redefining this classification and move to one based on human rights schools, which has more and better elements to understand human rights in the 21 st century.

Keywords: Human Rights; Generations Theory; Human Rights Schools, Universality.

\footnotetext{
${ }^{1}$ Artículo de reflexión.

${ }^{2}$ Doctor en Políticas Públicas. Profesor de la División de Estudios de Posgrado de la Facultad de Derecho y Ciencias Sociales de la Universidad Michoacana de San Nicolás de Hidalgo. Profesor de Cátedra del Instituto Tecnológico y de Estudios Superiores de Monterrey. México. https://orcid.org/0000-0002-3216-219X E-mail: torres0112@hotmail.com

*Cómo citar este artículo: Torres, J. (2018). De generaciones a escuelas: una nueva forma de concebir a los derechos humanos. Hojas y Hablas, (16), 97-112. DOI: 10.29151/hojasyhablas.n16a7
} 


\section{Introducción}

La clasificación de generaciones de derechos humanos ha orientado el entendimiento e interpretación de estos durante los últimos cuarenta años. Al pensar en derechos humanos, sus alcances, características, fuentes y limitaciones, es inevitable no acudir a la concepción generalizada y porque no, vulgarizada de estos: la primera, segunda, tercera, y demás generaciones. Al concebirlos como fruto de eventos históricos específicos, los derechos humanos han sido encapsulados, de manera ineludible, en un tiempo y espacio propios de un sistema político.

A poco más de cuarenta años de aparecida la teoría de generaciones propuesta por Vasak, esta se ha vuelto referente casi obligado en la discusión sobre los derechos humanos, ya sea desde un enfoque político, jurídico, filosófico, sociológico, o cualquier otro, acudir a ella es casi inevitable. Sin embargo, esta teoría deja vacíos que generan más incertidumbres que certezas, por ello, merece la pena replantearnos esta esquematización de derechos y en su lugar, avanzar a una concepción que nos permita comprender de forma más holística a los derechos humanos.

Por lo anterior, en este artículo expongo las ventajas de transitar de la teoría de generaciones, a la teoría de escuelas de derechos humanos propuesta por la profesora de derecho y antropología de la Universidad de Brighton, Marie-Bénédicte Dembour. Concebir a los derechos humanos como escuelas y no como generaciones, permitirá, como expondré más adelante, trascender la noción restrictiva de ciudadanía como existe hoy, para estar en condiciones de discutir una posible universalidad de los derechos humanos en un mundo de refugiados y migrantes.
La pregunta es ¿cuáles son los beneficios que aporta transitar de una teoría de generaciones a una de escuelas de derechos humanos? Para responder a esta pregunta se plantea la siguiente hipótesis: Abordar a los derechos humanos desde la teoría de escuelas, hace posible acceder a un entendimiento más holístico y completo de éstos enfocándolos en su justa realidad y ámbito espacial, limitaciones y contextos que delimitan y definen su contenido, y en última instancia su materialización en la sociedad.

En la primera parte de este trabajo se presenta un breve análisis sobre el origen de la teoría de generaciones, su autor e intenciones. En la segunda parte, se analizan los que considero, los tres problemas fundamentales de la teoría de generaciones: el reduccionismo histórico y el encubrimiento de la lucha, la ilusión de universalidad, y la obligación negativa y positiva del Estado. En la tercera parte, se analiza el contenido de la teoría de escuelas de derechos humanos: escuela naturalista, escuela deliberativa, escuela de protesta y escuela discursiva. Finalmente, se presentan algunas conclusiones.

\section{Aparición de las generaciones de derechos humanos}

Hablar de derechos humanos de primera, segunda, tercera, cuarta, generaciones, transporta al lector a un campo ampliamente discutido y al mismo tiempo aceptado en cuanto a la génesis de estos derechos. Al hablar de generaciones, no solo se hace referencia al "origen" de los derechos, sino también se invoca, casi de forma inconsciente, una jerarquización entre ellos, lo que lleva inevitablemente a una separación o fractura entre estos. Concebir a los derechos humanos como generaciones, provoca, entre otras cosas, que el Estado, pueda garantizar de forma parcial los derechos, al respecto, conviene citar el caso mexicano respecto 
a los derechos económicos, sociales y culturales durante el siglo XX:

En México, durante casi todo el siglo XX, los derechos económicos, sociales, culturales y ambientales (DESCA) fueron considerados por la doctrina y la jurisprudencia sólo como derechos programáticos de los que se desprendían obligaciones de hacer, económicamente costosas y por ello imposible de ser reclamados ante tribunales. (Gutiérrez, 2014, p. 91)

Esta concepción segmentada de los derechos humanos se fundamentó en lo que Gutiérrez denomina tesis historicistas (Gutiérrez, 2014, p. 91). Estas tesis encuentran su fundamento en un entendimiento lineal de la historia de los derechos humanos, así como una falta de análisis -convenientemente olvidado- de los eventos históricos desencadenantes de las generaciones de derechos. Aunado a lo anterior, se desarrolló un entramado sobre la supuesta diferenciación entre los derechos civiles y políticos, por un lado, y los derechos económicos, sociales y culturales por el otro, argumentando que los primeros implicaban accionas negativas del Estado -no hacer o interferir- y, lo segundos, acciones positivas -hacer o garantizar-, lo que dio como resultado una concepción sesgada de los derechos, haciendo posible que la exigibilidad de los derechos sociales -judicialización- fuera imposible.

Como ejemplo de los problemas de la concepción de generaciones de derechos humanos en la actualidad, merece la pena transcribir lo expuesto por Gómez Isa, quien partiendo de una concepción "generacionista" de derechos humanos señala lo siguiente respecto a los derechos de tercera generación:
La palabra clave de estos nuevos derechos es la palabra solidaridad, lo que no significa que tan solo estos derechos sean los vehículos para promocionar esa solidaridad. También los derechos humanos de las dos primeras generaciones deben servir para plasmar ese necesario valor en una sociedad internacional tan dividida como en la que estamos viviendo actualmente. Pero lo que sí es cierto es que, como afirma Gros Espiell, "quizá los derechos de la tercera generación requieran la solidaridad en un grado mayor". Como pone manifiesto en el mismo sentido Antonio-Enrique Pérez Luño, 'los derechos de tercera generación tienen como principal valor de referencia a la solidaridad. Los nuevos derechos humanos se hallan aunados entre sí por su incidencia universal en la vida de los hombres y exigen para su realización la comunidad de esfuerzos y responsabilidades a escala planetaria. Sólo mediante un espíritu solidario de sinergia, es decir, de cooperación y de sacrificio voluntario y altruista de los intereses egoístas, será posible satisfacer plenamente las necesidades y aspiraciones globales comunes relativas a la paz, a la calidad de vida' (Gómez, 2003, p. 14).

La postura de Gómez (2003) es generacionista, él parte del supuesto de que los derechos humanos están delimitados por generaciones históricas y con ello, sella el destino de estos. Al citar a Antonio-Enrique Pérez Luño, Gómez parece señalar, uno de los grandes obstáculos y problemas para los derechos humanos concebidos por la teoría de generaciones: su exigencia y materialización. Baste para demostrar lo anterior lo señalado por él, cuando establece que los derechos de tercera generación requieren "esfuerzos y responsabilidades a escala planetaria”, con ello, no solo los derechos de tercera generación, sino también los de segunda, quedan anclados a la siempre elusiva capacidad presupuestal de los Estados, y lo que es peor, a su buena voluntad. 
Por otro lado, concebir a los derechos humanos como generaciones, complica garantizar en el plano material los derechos económicos, sociales y culturales, pero aún más, para los llamados derechos humanos de tercera generación, los cuales, siguiendo a la Agencia de la ONU para los Refugiados ACNUR (2018) podemos resumir en:

Derecho al desarrollo sostenido: modelos y estructuras económicas que, además de generar beneficios propios, permitan el acceso a servicios básicos y garanticen la sostenibilidad del planeta. Derecho a la autodeterminación de los pueblos: el que tienen los países de determinar libremente su condición política y su modelo social y económico. Derecho a la paz: entendido no solo como ausencia de guerra, sino también como la puesta en marcha de procesos positivos que fomenten la participación, el diálogo, la inclusión, la cooperación y la superación de conflictos. Derecho a la protección de los datos personales: llama la atención sobre los eventuales peligros y abusos a los que se exponen las personas ante el cada vez más extendido proceso de informatización. Derecho al patrimonio común de la humanidad: alude al acceso a los bienes de tipo material e inmaterial que constituyen un legado de especial relevancia para comprender la evolución humana. Derecho a gozar de un medioambiente sano: Todas las personas tienen derecho a disfrutar de ambientes sanos, limpios y sostenibles.

Antes de continuar y analizar los retos que afrontan en la actualidad los derechos humanos concebidos como generaciones, conviene primero señalar rápidamente las condiciones que le dieron origen. Para comprender el génesis de los derechos humanos y su concepción por generaciones, debemos remontarnos a los años setenta. En noviembre de 1977, el entonces director de la División de Derechos Humanos de la UNESCO, Karel Vasak, presentó un artículo en el UNESCO Courier donde se refería a una tercera generación de derechos humanos, generación recién identificada por el director general de este organismo AmadouMathar M'Bow. En dicho artículo, Vasak se da a la tarea de dotar de contenido a esta generación "recién descubierta”, razón por la cual, primero debía justificar la existencia de una primera y segunda generaciones que le dieran soporte (Jensen, 2015). En este artículo, Vasak expondría:

Los derechos proclamados en la Declaración Universal caen en dos categorías: por una parte, derechos civiles y políticos y, por la otra, económicos, sociales y culturales (...). La primera generación concierne a "derechos negativos", en el sentido de que su respeto requiere que el Estado no haga nada que pueda interferir con las libertades individuales, y corresponde en general a los derechos civiles y políticos. La segunda generación, por el otro lado, requiere acciones positivas por parte del Estado para ser implementadas, como es el caso de la mayoría de los derechos sociales, económicos y culturales. La comunidad internacional se embarca ahora en una tercera generación de derechos humanos que bien podría llamarse "derechos de solidaridad". (Vasak, 1977, p. 29)

En aquel entonces la clasificación de generaciones propuesta por Vasak ofrecía respuesta rápida y sencilla a los debates en torno al naciente "derecho al desarrollo", derecho que se relacionaba con la paz, el medio ambiente, el patrimonio común de la humanidad y la libre determinación de los pueblos (Rabossi, 1997, p. 42). Otra cuestión 
de importancia a la que dio respuesta la creación de una tercera generación de derechos, fueron los retos nacientes fruto de los eventos descolonizadores acontecidos en los años sesenta con la aparición en la escena internacional de los llamados países en vías de desarrollo (Gómez, 2003, p. 13).

Gracias a su forma de entender la evolución de los derechos humanos, la clasificación de generaciones hacía posible argumentar que este "incremento" de derechos no era arbitraria, sino se trataba de una etapa más del proceso histórico de los derechos humanos, etapa que encontraba su punto de partida a fines del siglo XVIII, con los derechos civiles y políticos, y continuado en el siglo XX, con lo derechos económicos, sociales y culturales (Rabossi, 1997, pp. 42-43).

\section{Problemas con las generaciones de derechos humanos}

Antes de señalar las ventajas de la teoría de escuelas de derechos humanos, es necesario señalar los inconvenientes de la clasificación de generaciones. Para exponer mejor lo anterior, me referiré a continuación a tres problemas fundamentales de la clasificación de generaciones: el reduccionismo histórico y el encubrimiento de la lucha, la ilusión de universalidad, y la obligación negativa y positiva del Estado.

El reduccionismo histórico y el encubrimiento de la lucha. Los derechos humanos entendidos a partir de la clasificación de generaciones parecen apuntar a una génesis histórica -primera generación siglo XVIII y segunda generación siglo XX- así como a una evolución de estos en el tiempo. El problema con esta concepción es que si se acude a los eventos históricos emblemáticos citados por Vasak y otros partidarios de la clasificación de generaciones, se puede observar que estos eventos fueron excluyentes y clasistas. Al respecto del origen clasista y excluyente de los derechos humanos, Costas Douzinas presenta un análisis en forma de siete tesis, el cual considero imprescindible para comprender mejor el origen excluyente de los derechos humanos (Douzinas, 2006). Analicemos a continuación algunos de estos documentos que fueron concebidos con un componente excluyente y clasista. Los documentos fundacionales estadounidenses, por ejemplo, excluían a los esclavos y las mujeres. El contenido del artículo primero de la Declaración de Derechos de Virginia de 1776, que dice: "todos los hombres son por naturaleza igualmente libres e independientes y tienen ciertos derechos innatos", debe leerse y entenderse así, solo hombres, es decir, varones blancos, no mujeres, no esclavos. La interpretación a los textos subsiguientes en Estados Unidos -Constitución y Enmiendas-, sería la misma, incluso la Guerra de Secesión que liberó jurídicamente a los esclavos en la segunda mitad del siglo XIX, no lograría suavizar la interpretación excluyente de los textos, dando lugar a casos emblemáticos como el Plessy vs Ferguson -finales del siglo XIX- con la aborrecible sentencia de "separados pero iguales" que legitimaba jurídicamente el racismo (Scott, 2004), hasta las leyes de segregación racial, que se mantendrían vigentes hasta la década de los sesenta del siglo XX, es decir, hicieron falta más de cien años de historia para que la interpretación de los textos permitiera la inclusión de los sectores desfavorecidos de la sociedad.

\footnotetext{
${ }^{2}$ Nunca pueden faltar la obligada referencia a textos fundamentales como la Declaración de Derechos del Estado de Virginia de 1776, la Declaración de Independencia Norteamericana del 4 de julio de 1776, la Declaración de los Derechos del Hombre y el Ciudadano de 1789 y por supuesto, la Declaración Universal de los Derechos Humanos de 1948.

${ }^{3}$ Para la cita de la Declaración de Derechos de Virginia me baso en el texto de jurídicas de la UNAM, disponible en: https://archivos.juridicas.unam.mx/www/bjv/libros/6/2698/21.pdf
} 
La Revolución francesa por su parte, además de sus efectos históricos desagradables a veces convenientemente olvidados, no incluía a las mujeres. Olympe de Gouges, consciente de su exclusión, publicó su propia versión, la Declaración de los Derechos de la Mujer y de la Ciudadana, tristemente, su esfuerzo se vería obstaculizado por su ejecución durante la era del terror. Igualmente, la Declaración Universal de los Derechos Humanos vio la luz en un periodo histórico plagado aún de racismo y colonialismo, por lo que difícilmente podemos acudir a ella como el origen material de la inclusión y la universalidad.

El problema esencial con la lectura de estos eventos históricos desde la clasificación de generaciones es que sugiere un nacimiento espontáneo y geolocalizado en occidente de estos derechos, reduciendo los eventos históricos solo a una porción -la que legitima el discurso- y que excluye convenientemente la parte represora, por ello, encubre el origen excluyente y clasista de los derechos, invisibilizando la lucha requerida para obtenerlos. Los derechos humanos emanados de estos eventos nacieron como privilegios de unos pocos, así, incluir en ellos al resto que fue olvidado no fue mera cuestión de evolución histórica, sino más bien, parafraseando a Žižek (Žižek, 2008), de una lucha incesante y a veces dolorosa de la parte sin parte para conseguir lo que en un principio les fue negado.

La ilusión de universalidad. Partiendo del problema del reduccionismo histórico y el encubrimiento de la lucha que señale anteriormente, se puede cuestionar la idea de universalidad de los derechos humanos. La concepción actual de los derechos humanos entiende estos como derechos inherentes, inalienables, imprescriptibles y universales, sin embargo, estas características son descartables atendiendo al origen de la primera y segunda generación (Algan, 2004), y las que le sigan: tercera y cuarta, quinta, así como al respeto y materialización de estos. Considerar los derechos humanos como universales desde la clasificación de las generaciones, encubre el problema de que no lo son. Los derechos humanos adquieren su "poder" del campo de fuerza del Estado, de sus fronteras, de su territorio, sin él, se desfiguran en reclamos enérgicos y en buenas intenciones. Aquí me refiero a la ciudadanía, sin ella, los derechos humanos pierden su magia.

La ciudadanía petrifica los derechos humanos, los ancla en el monolito de las leyes e instituciones. Esto tiene un efecto doble en la universalidad. Por un lado, los derechos humanos se ven desposeídos de su mística universal y se mimetizan con lo local, existiendo solo en la medida en que el Estado nacional y sus instituciones son capaces de traducirlos -tanto legal como materialmente- $y$, por el otro, implica que su existencia está sujeta a la positivación de las normas, a su "redacción" en un texto constitucional o legal que permita derivar de él, alguna sombra de autoridad que posibilite exigirlos, así como señalar su inexistencia.

Aun si somos partidarios de la universalidad de los derechos humanos, debemos considerar que estos requieren algún grado de positivación. $\mathrm{Al}$ respecto, ni siquiera un iusnaturalista como

\footnotetext{
${ }^{4}$ La Revolución Francesa' por ejemplo' no logró materializar lo expuesto en la Declaración de los Derechos del Hombre y del Ciudadano. Apenas años después comenzaría la llamada era del terror (1793) y en 1799, Napoleón daría un golpe de Estado que llevaría a Europa a la guerra' guerra que daría como saldo un intento extremo de regresar al absolutismo (Congreso de Viena de ${ }^{1815)}$ y borrar todo indicio de la Revolución y sus componentes liberales.
} 
Mauricio Beuchot puede escapar a la necesidad de "traducir" los derechos humanos a leyes o normas (Beuchot, 2000). Para que estos derechos existan, deben existir en las leyes y esto nos lleva al segundo efecto de la ciudadanía en la universalidad que mencioné en el párrafo anterior. Al final de cuentas, si los derechos humanos requieren ser positivados en el derecho local, eso implica que este habrá de adecuarse a las condiciones nacionales y con ello, su alcance estará limitado por la "membresía" de la ciudadanía. Ahí radica la paradoja: nosotros deseamos que las leyes sean reflejo de nuestros deseos y aspiraciones, que contengan todo derecho humano posible, pero al hacerlo, reducimos estos derechos a una dinámica local que termina por definir las condiciones bajo las cuales estos derechos habrán de entrar en la agenda gubernamental, en las leyes, en la sociedad, etc.

La obligación negativa y positiva del Estado. Este, como expone Rabossi, es uno de los mitos más dañinos de la clasificación de generaciones hacia los derechos humanos (Rabossi, 1997, p. 49). Como señale en las primeras líneas de este artículo, Vasak consideró que los derechos humanos de primera generación requerían “acciones negativas", mientras los de segunda generación "acciones positivas". Por alguna razón, se aceptó sin mucha discusión que para garantizar los derechos civiles y políticos el Estado debía abstenerse, no entremeterse, quitarse de en medio; por el otro, los derechos económicos, sociales y culturales requerían una postura de demanda hacia al Estado, es decir, deben ser exigidos, así, derivado de la lectura "separatista" entre ambos, los derechos de tercera generación serían tanto positivos como negativos. El problema con la visión anterior es que separa artificialmente a los derechos humanos, dando impresión que pueden ser respetados por secciones, es decir, posibilita una interpretación sesgada de los derechos, haciendo posible para el Estado argumentar en contra de su materialización.

Pensar los derechos humanos en términos de hacer y no hacer, de positivos y negativos, es reduccionista y atenta contra la realidad de estos. Por un lado, tanto los derechos civiles y políticos como los económicos, sociales y culturales requieren ambos de estrategias positivas y negativas. Por ejemplo, no puedo ir a votar si el Estado no ha dispuesto casillas, boletas electorales, funcionarios de casilla capacitados, tiempos de propaganda para partidos, gastos de campaña, por otro, para mantenerme sano, también requiero de una acción negativa del Estado, en, por ejemplo, que este se abstenga de contaminar, de afectar áreas naturales protegidas, así, la visión negativa y positiva presenta una imagen falsa y marginal de los derechos haciendo que estos pueden ser violentados por el Estado con mayor facilidad.

\section{Escuelas de derechos humanos}

De acuerdo con la teoría de escuelas de derechos humanos presentada por Dembour (2006), los derechos humanos no deberían ser definidos por lo que creemos que significan, sino por lo que son en la realidad (p. 233). Dembour identifica seis características principales en la noción de derechos humanos: son derechos morales, existen independientemente del reconocimiento social, son algo que los seres humanos poseen, están basados en la naturaleza humana, descansan en consensos legales y son transformables en derechos jurídicos (Dembour, 2006, pp. 234-235). La autora se avoca a identificar elementos clave en la noción prevaleciente de derechos humanos a partir de los cuales construye un entendimiento más holístico de los derechos. Dembour identificó diversas características que mezcladas dan origen a distintas definiciones de derechos humanos, definiciones que no poseen en la realidad una relación entre sí, por ello, nos enfrentamos, dice Dembour, a una 
competición entre conceptos de derechos humanos (Dembour, 2006, p. 236). Para resolver este dilema, la autora propone concebir a los derechos humanos no como generaciones, sino como escuelas, teniendo cada una de estas, características propias. Los derechos humanos entendidos desde escuelas, presentan a estos en cuatro vertientes no excluyentes: a) escuela naturalista; b) deliberativa; c) de protesta o resistencia y; d) discursiva (Dembour, 2006; Arias, Muro y Buganza, 2015).

\subsection{Escuela naturalista}

La escuela naturalista considera a los derechos humanos como universales e inherentes. Parte de suponer que los derechos se basan en la naturaleza humana. Pensadores como Cicerón o John Locke, dotan a esta escuela de contenido, y en términos contemporáneos, tiene a Jack Donnelly, Alan Gewirth y Mauricio Beuchot como principales exponentes. Igualmente, los textos fundaciones de la clasificación de generaciones tienen corte naturalista, pues asumen a los derechos humanos como universales, inherentes e interdependientes basados en la dignidad humana.

Como la clasificación de generaciones se fundamenta en una concepción naturalista de los derechos, las críticas señaladas con antelación se refieren a esta escuela en particular, por lo que no me detendré más en ella. Sin embargo, merece la pena detenerse en dos autores contemporáneos que intentan "actualizar" la concepción naturalista de los derechos humanos, me refiero Mauricio Beuchot y Javier Saldaña. Su objetivo es resolver el dilema sobre la fundamentación de los derechos humanos. Este dilema se centra en la cuestión del origen, es decir, en conocer la raíz, la esencia, la fuente de los derechos humanos más allá del mero documento legal. Ante este dilema, caben dos posibilidades: los derechos humanos provienen de valores morales atemporales, o su fundamentación proviene únicamente de los sistemas jurídicos. Para resolver este dilema, se busca, en sus palabras: "un iusnaturalismo vivo, que busca la universalidad para esos derechos, pero que piensa que lo universal se da de manera concreta, situada, encarnada en lo histórico. Es un iusnaturalismo analógico" (Beuchot y Saldaña, 2000, p. 11-12).

El iusnaturalismo analógico se fundamenta en dos partes, por un lado, el reconocimiento de la universalidad de los derechos y por el otro, la positivación del sistema jurídico. Aquí, el deseo de los autores es garantizar los derechos humanos en dos aspectos: inherencia y universalidad, y en su componente jurídico. Sin los primeros, los derechos humanos quedarían a merced de los gobernantes, quienes en cualquier momento podrían cancelarlos o abolirlos, pero sin los segundos, los derechos carecerían de fuerza, existiendo solo como meros enunciados vacíos, por ello, se requiere una convergencia entre la moral y el derecho, para garantizar un punto medio que permita materializar los ideales de la humanidad en derechos humanos.

A pesar del interés renovado de Beuchot y Saldaña por encontrar un fundamento metajurídico a los derechos humanos, podemos decir que estos autores caen al final, en la inevitable fundamentación jurídica y positiva de los derechos, pues reconocen que sin normas jurídicas que los contengan, llevar estos a la realidad es imposible.

\subsection{Escuela deliberativa}

Para la escuela deliberativa, los derechos humanos son "potencialmente" universales (Dembour, 2006, p. 254), en tanto que dependen de un consenso para ser alcanzados. De acuerdo con esta escuela, los derechos humanos son resultado de la deliberación política entre los participantes, deliberación que, siguiendo a Habermas, exige para estos derechos "ser declarados democráticamente 
y trasplantados de manera constructiva en el marco de la comunidad política" (Habermas, 2010, p. 111).

En esencia, la escuela deliberativa implica que los derechos humanos, si bien poseen un origen moral o metajurídico, estos requieren forzosamente de la positivación a partir del consenso de los integrantes -grupos sociales, agrupaciones civiles, sectores vulnerables, agentes gubernamentales, etc.-, es a partir de este consenso, es decir, ejercicio deliberativo, que los derechos humanos llegan a la agenda gubernamental y se instauran en el entramado jurídico. Lo que nos permite observar e identificar esta escuela, es que los derechos humanos no "emergen" de la nada, sino surgen de los deseos y promesas no materializados por el Estado y sus agentes, arrojando luz a los asuntos pendientes en la materia.

Para Habermas, los derechos humanos están ligados a la idea de dignidad humana y en última instancia a una idea moral anterior a la positivación de los derechos, sin embargo, que los derechos partieran de una fundamentación moral no los hace derechos abstractos o derechos aspiracionales, sino que para estos derechos "ser declarados democráticamente y trasplantados de manera constructiva en el marco de una comunidad política" (Habermas, 2010, p. 111), así, en palabras de Habermas, los derechos humanos se muestran como el dios Jano, con una cara que mira al mismo tiempo a la moral y otra al derecho, por tanto, adoptan la forma de

Derechos subjetivos positivos, penalmente tutelados, que garantizan las expectativas y los espacios de libertad del individuo. Pretenden ser concretados por la vía de la legislación democrática, especificados en cada caso por la jurisprudencia y realizados por las sanciones estatales. Los derechos humanos delimitan, por tanto, exactamente aquella parte de la moral ilustrada que, traducida al soporte del derecho coactivo y a la robusta figura de efectivos derechos fundamentales, puede ser realidad política (Habermas, 2010, p. 111).

Resalta entonces, que, para Habermas, los derechos humanos, pese a estar fundamentados en la moral, requieren para existir plenamente de una positivación, es decir, requieren implantarse en las normas jurídicas de la sociedad, por ello, estos derechos son deliberativos, ya que, para alcanzar la positivación de algún derecho, se requiere llegar a consenso. Sin duda, el pensamiento de Habermas es claro en cuanto al "origen" deliberativo y consensual de los derechos humanos, lo que nos lleva a la universalidad de estos en aras de alcanzar su realización.

Pasemos ahora a los postulados de Sally Engle Merry, quién, al igual que Habermas, considera que la positivación de los derechos humanos solo es posible a través de diálogo y consenso, pero no solo eso, sino requiere que estos derechos sean "tropicalizados" es decir, adaptados al contexto local, esto lo llama Engle Merry la "paradoja de hacer los derechos humanos vernáculos”, ella define esta paradoja de la siguiente manera:

(...) para que sean aceptados (los derechos humanos), deben ser adaptados al contexto local y resonar con el andamiaje cultural de la localidad. Sin embargo, para que puedan formar parte del sistema de derechos humanos, deben enfatizar el individualismo, la autonomía, la decisión, la integridad corporal y equidad, ideas que están incrustadas en los documentos legales que constituyen los derechos humanos. (Engle, 2006, p. 221) 
Abonando a la idea de consenso, Engle Merry distingue entre tres tipos de procesos culturales que constituyen lo que ella llama "la traducción global-local” (Engle, 2006, p. 19-21), que no es otra cosa que llevar de lo general a lo particular la implementación de los derechos humanos. El primero, es la "construcción del consenso transnacional", en él se engloban los documentos oficiales en derechos humanos, los cuales, fruto del consenso internacional son aceptados internacionalmente, tales como Cartas, Convenciones, Tratados, Resoluciones, Declaraciones, entre otras. La segunda, son los "trasplantes de programas transnacionales" que se pueden resumir como aquellos servicios o programas, así como innovaciones legales que son implementadas en un lugar para después ser trasplantadas a otra. El tercero, es la "localización del conocimiento trasnacional" mediante actores nacionales y locales que participan en eventos trasnacionales y regresan a casa con lo aprendido. Estos últimos juegan un papel capital, pues son ellos los que participan de muchas de las discusiones trasnacionales, discusiones en las cuales se llega a acuerdos y consensos de nivel internacional.

Para Engle Merry, los derechos humanos son fruto de un consenso social local, nacional e internacional, esferas que en última instancia se trastocan y permiten, por un lado, llevar lo acordado en los niveles internacionales a las realidades locales y por el otro, tomar las experiencias locales exitosas (trasplantes de programas trasnacionales) y llevarlas al plano internacional.

Tanto la escuela naturalista como la deliberativa, si bien difieren en el tratamiento de diversos temas, entre ellos el carácter universal de los derechos humanos y la forma de llegar a su aplicación, parecen compartir la postura relativa a la positivación de los mismos en cuanto condición infranqueable para su realización

En conclusión, la escuela deliberativa nos permite observar una postura en la que los derechos humanos no son universales e inherentes, sino que solo poseen dichas cualidades en el discurso, en un discurso occidentalizado de derechos humanos parafraseando a Engle Merry. De tal suerte que los derechos humanos en la práctica dependen más del consenso dentro de la comunidad y de esta con los actores locales, nacionales e internacionales en la materia para poder existir y aplicarse, por ello, son universales e inherentes en cuanto a su propósito y aspiración, pero en la actualidad, requieren de un proceso de diálogo y discurso entre los actores para lograr el reconocimiento de estos por parte del Estado, de tal suerte que los derechos humanos no están dados sino que son reconocidos por la autoridad en la medida en que se logra convencer a esta de la importancia de los derechos. Por lo anterior, uno no de los grandes aportes de dicha postura, es mostrar la argumentación necesaria de los derechos por parte de los actores para lograr que la autoridad reconozca su existencia, hay por ello un proceso de diálogo y deliberación entre los actores para llegar a un consenso sobre los derechos.

\subsection{Escuela de protesta}

La escuela de protesta o resistencia parte de un componente de insatisfacción, de un continuo deseo inalcanzable. Los derechos humanos nunca estarán completos, siempre habrá algo que agregar a ellos, por tanto, los derechos humanos dependen del antagonismo ante el statu quo, de evaluar la realidad y anteponer a ella un componente de insatisfacción constante, de ahí el avance de estos. Los derechos humanos se estancan en el momento en que se consideran completos.

Costas Douzinas, exponente de esta escuela, 
realiza un conciso análisis de los retos de los derechos humanos a partir de su origen. En esencia, para Douzinas los derechos humanos poseen un componente nacionalista y estatal del cual no pueden escapar, por lo tanto, los derechos humanos están anclados a una dinámica nacionalista que los dotan de contenido local, no universal. Para Douzinas (2006)

Los derechos humanos estaban inicialmente vinculados a específicos intereses de clase y eran las armas ideológicas y políticas en la lucha de la emergente burguesía contra el despótico poder político y la estática organización social. Pero sus presupuestos ontológicos, los principios de igualdad y libertad humanas, y su corolario político, la pretensión de que el poder político debía someterse a las demandas de la razón y el derecho, se ha convertido hoy en una parte de la ideología de la mayor parte de los regímenes contemporáneos trascendiendo su parcialidad (pp. 309-310).

Por otro lado, estos derechos son fruto de las luchas locales y por tanto de su propio entorno, así, la universalidad que pretende la escuela naturalista no puede trasplantarse a otros lugares sin un efecto a veces negativo que puede llevar a la imposición de contenidos jurídicos.

La escuela de protesta nos permite observar que los derechos se alcanzan por la lucha, por el antagonismo, por el reconocimiento de la diferencia. Douzinas es enfático en señalar que los derechos humanos poseen un componente de clase y por ello, un contenido dominante. Sin el reconocimiento de este contenido no sería posible avanzar en la categorización de nuevos derechos. Con ello, Douzinas nos muestra que los derechos humanos no surgen de generaciones "espontaneas" en el tiempo, ni mucho menos se suceden unas a otras, sino que avanzan y retroceden, luchan y se abren camino a partir del reconocimiento de lo faltante, de ahí que la clasificación de generaciones olvide que los derechos humanos son fruto de la insatisfacción, de la diferencia y no de una mera conquista simbólica.

\subsection{Escuela discursiva}

Finalmente, en la escuela discursiva destacan los trabajos de Jaques Derrida, Makau Mutua y la propia Dembour. Para esta escuela, los derechos no pueden ni deben ser universales. La universalidad en sí misma contiene un componente de imposición y dominación propio de la cultura que lo impulsa. Para comprender mejor los postulados de esta escuela, comenzaremos con un breve análisis del pensamiento de Jacques Derrida, en su obra On cosmopolitanism and forgiveness (Derrida, 2001).

En On cosmopolitanism and forgiveness, Derrida, retomando eventos internacionales propios a su tiempo y entorno (1996-1999 en el tiempo en que pronunció dicha postura), como el problema de refugiados en Europa, particularmente en Francia, el apartheid en Sudáfrica y la persecución de escritores en Argelia, trata dos conceptos fundamentales, por un lado el "cosmopolitismo" (cosmopolitanism) y por el otro, "el perdón" (forgiveness), y analiza en cada uno de ellos, lo que él considera una contradicción inherente tanto en su definición como en su utilización.

Derrida comienza su obra criticando la idea de cosmopolitismo, término sumamente popular, pero al mismo tiempo ambiguo e inexistente. Retoma el caso de Argelia, en el que numerosos asesinatos de escritores llevaron a la necesidad de crear un Parlamento Internacional de Escritores, que demandaron seguridad y mejores condiciones 
para ellos mediante la existencia de una red de ciudades para asilo. El nombre "ciudades para asilo", dice Derrida, "parece estar escrita en letras de oro en el corazón mismo el parlamento internacional de escritores" (Derrida, 2001, p. 4), sin embargo, no existe más que en el papel. Como sustento, el autor recurre a Hannah Arendt, quien define el derecho de los refugiados como "sagrado", pues es natural, ante el peligro, intentar huir de él para salvarse; siguiendo este análisis, Derrida propone que existe un anacronismo en el término de refugiado, y al mismo tiempo, hipocresía por parte del Estado para garantizarlo, pues el Estado sigue sustentando el principio de soberanía, "el principio supremo de sus leyes" bajo las cuales el asilo no puede existir.

El caso de Francia apunta Derrida, no es mejor que otros lugares de Europa, ello pese a que históricamente ha contado con un número más elevado de refugiados que otros países. Lo anterior, debido a que la ayuda que proporciona no se basa en la ética, sino en el interés, que, en este caso, va de la mano con un desarrollo económico y una necesidad de más trabajadores (Derrida, 2001, p. 10). De ahí que el derecho de refugiados, y en última instancia, los derechos humanos, siguiendo los postulados de Derrida, se encierren a una dinámica procedimental gobernada por estrictos preceptos legales. Incluso, el autor va más allá e identifica una dinámica de interés demográficoeconómica que determina las condiciones bajo las cuales habrán de recibirse los refugiados, condiciones que, como premisa principal, decretan un beneficio económico nulo, para aquellos "afortunados" en recibir dicho asilo.

Lo anterior nos permite iluminar uno de los puntos centrales de la escuela discursiva o disidente: la universalidad de los derechos humanos existe solo como recurso discursivo, e inclusive, como lo veremos más adelante, la idea misma de universalidad, a diferencia de los postulados de las escuelas deliberativas y de protesta, representa un peligro real para su materialización. Pero, antes de analizar dicho punto, sigamos con lo expuesto por Derrida.

Derrida sigue el pensamiento de Kant, en tanto que el cosmopolitismo está delimitado por la estructura del Estado nación, el cual, al estar limitado por fronteras, rechaza por principio a todo aquel que haya nacido fuera de ellas. Hasta aquí, los postulados son parecidos a los expuestos por la escuela de protesta, en tanto que existe una dualidad opuesta entre soberanía y Estado, entre derechos humanos y ciudadanía, sin embargo, la escuela discursiva no se queda ahí. Al analizar la segunda parte de la obra, nos encontramos con diferencias sustanciales.

En la segunda parte de la obra On forgiveness, (en el perdón), Derrida se adentra al problema del lenguaje. Abordando el término de "perdón", el autor es capaz de señalar el problema relativo a la universalidad en cuanto al entendimiento del término. Derrida nos dice que, en el periodo de la posguerra, el término perdón se popularizó, pero lo hizo desde una perspectiva hebrea del lenguaje, ésta por supuesto, no representa la religión dominante del mundo, sin embargo, esta: "ya se ha convertido en el lenguaje universal de la ley, de la política, de la economía y de la diplomacia: y al mismo tiempo el agente y el síntoma de esta internacionalización" (Derrida, 2001, p. 28).

Lo que nos dice el autor es que lo que consideramos como universal, como incuestionable, o si se quiere, como real e incontestable en cuanto al contenido del término, proviene de la interpretación del poderoso y no de un "descubrimiento" 
moral o ético, así, lo que entendemos como perdón o como crímenes contra la humanidad, dice Derrida, provienen de la tradición impuesta por el poderoso, de tal suerte que es posible encontrar rastros de cristianismo en términos como "vecino" o "prójimo", esto nos lleva a la pregunta ¿por qué imponer estos conceptos o apreciaciones a culturas que no poseen orígenes europeos o bíblicos? (Derrida, 2001, p. 31).

Para responder a esta pregunta, Derrida recurre a la "hipocresía" del término. La hipocresía a la que se refiere el autor subyace en la idea misma que da origen al perdón, es decir, se pide el perdón, pero este solo se otorga a ciertos actos, quedando otros como "imperdonables", así, el acusado -sujeto, Estado, gobierno, etc.- , al pedir perdón, no lo hace por iniciativa propia sino por el beneficio que ello le reporta, así, al disculparse en los términos señalados, deja de ser "malvado" para ser "arrepentido", lo que nos lleva una vez más a los postulados de herencia hebrea.

Lo que permite vislumbrar el pensamiento de Derrida, es la importancia que yace en el lenguaje y en la interpretación que de él se hace. Ejemplificado en el término "perdón" Derrida descubre una tradición occidentalista-hebrea, propia del creador y dominador del término -Estados Unidos principalmente-, lo que en última instancia nos lleva a una imposición de los valores y posiciones del fuerte hacia el débil. Lo anterior se ejemplificará con mayor claridad con el pensamiento de otro autor representante de esta escuela: Makau Mutua.

Al respecto, Makau Mutua relata lo siguiente: Lo que esta verdad establece es la dificultad de realizar juicios transculturales sobre normas que tienen que ver con lo social, lo político, lo económico, lo cultural y el espiritual comportamiento de los individuos y las sociedades. Intentar construir creencias y doctrinas universales -o presentar un particular credo o doctrina como universal- corre el riesgo de destruir o diezmar distintos universos. El reclamo de un orden universalista es una posición extremadamente engañosa, si no totalmente imposible. Por ello es que intentar crear un consenso internacional sobre lo que constituye la dignidad humana debe ser abordado con matices, apertura mental, y con la complejidad que merece (Mutua, 2002, p. ix)

Lo que Mutua nos explica, es que lo universal en los derechos humanos es un componente local globalizado. Este componente local lleva implícito el deseo de imponer una definición común, un elemento ajeno al lugar al que se aplica, por ello, los derechos humanos llevan consigo una definición de las clases dominantes. El que domina busca imponer su contenido, dotarlo de legitimidad ante los otros y hacerlo pasar por universal, de ahí que esta escuela se sirva del lenguaje como herramienta principal.

Al igual que Mutua, Marie-Bénédicte Dembour, considera que tanto las pretensiones de universalidad como de apropiación del lenguaje son peligrosas. Para empezar a comprender por qué, analicemos brevemente sus conclusiones. A esta autora debemos la clasificación sobre las escuelas de derechos humanos antes analizadas, ella llega a una conclusión bastante interesante sobre los postulados de estas: "en conclusión, las escuelas se superponen de diversas formas y podría decirse que son parientes de la misma familia" (Dembour, 2006, p. 261). Por tanto, Dembour considera que los derechos humanos no significan una cosa sino muchas, de ahí que la definición de ellos dependa más de la postura de quien intenta definirlos. 
Los derechos humanos pueden ser universales en el sentido naturalista y positivos en el sentido de protesta o resistencia. Por contradictorio que ello pueda parecer, es entendible, dice Dembour, que las diversas escuelas de derechos humanos se intercalen entre sí, inclusive, ella concibe dicho entrelazamiento como favorable, lo que acentúa al retomar a Wittgenstein: "Al girar un hilo torcemos fibra sobre fibra. Y la fuerza del hilo no reside en que las fibras corran a todo lo largo de su longitud, sino en la superposición de muchas fibras" (Dembour, 2006, p. 261). En consecuencia, no existe una sola definición de derechos humanos, más bien, estas definiciones pueden enriquecerse del análisis de las diversas escuelas, en tanto que estas últimas permiten vislumbrar retos y problemas relativos a la formulación y entendimiento de estos derechos, lo que permite a sus defensores elegir vías adecuadas para su realización.

$\mathrm{Al}$ respecto de dichos retos, Dembour retoma el problema de la universalidad. La universalidad es deseable si se quiere, desde la perspectiva naturalista, sin embargo, como ya lo apuntaba el mismo Mauricio Beuchot con su iusnaturalisrmo analógico, los derechos humanos requieren ser positivados, llevados a la norma y ello implica un ejercicio de debate entre las posturas que guardan los actores -escuela deliberativa-, la cual muchas veces se impone por medio de la manifestación, y la protesta - escuela de protesta- y que sin duda, conlleva una carga de discurso propia del capitalismo occidental en tanto creador y defensor de dichos postulados -discursiva-, todo lo anterior nos lleva al problema de la aplicación de los derechos humanos.

Sin duda, se puede considerar que los derechos humanos son inherentes y universales, el reto radica en no caer en alguna de las trampas propias de la definición, lo que llevaría a legitimar el discurso del fuerte sobre el débil e inevitablemente, a descalificar culturas ajenas a nuestra herencia, lo que destruye, paradójicamente, el principio de universalidad.

Lo que la escuela discursiva nos permite comprender, es que la universalidad pretendida por la escuela naturalista $y$, potencialmente por la deliberativa, no es imparcial, sino que lleva en sí un componente que busca imponer una cierta condición de clase, un objetivo de dominación a partir del lenguaje. De ahí que esta nos permita realizar un análisis crítico de la universalidad y, sobre todo, de su aplicación, como lo es el caso de la invasión de Estados Unidos a Irak, y en general, de la intromisión del occidente en el medio oriente y en otros conflictos a lo largo de este siglo.

\section{Conclusiones}

Los derechos humanos deben ser pensados desde sus componentes, características y posibilidades, así como de sus deficiencias, limitaciones e intenciones. A partir de la teoría de escuelas es posible acceder a un entendimiento más holístico y completo de los derechos humanos, no así a partir de la clasificación de generaciones.

La teoría de escuelas de derechos humanos nos permite comprender que los derechos no surgen por el mero paso del tiempo, así como tampoco se esparcen de manera uniforme y progresiva por el resto de los países. Igualmente, las teorías de escuelas desnudan la mentira sobre la universalidad de los derechos, pues nos permite observar que los derechos humanos existen y "habitan" en la ciudadanía, no así en la supuesta dignidad humana. Por ello, carecer de ciudadanía es carecer de derechos humanos, lo que queda demostrado en la realidad que padecen los inmigrantes y la enorme cantidad de refugiados. 
Quizá uno de los mayores aportes del enfoque de escuelas de derechos humanos, radique en la incapacidad de concebir a los derechos humanos como universales. Con excepción de la escuela naturalista, el resto de las escuelas concibe solo como una posibilidad la universalidad, y en el caso de la escuela discursiva, esta incluso se convierte en un riesgo. La mentira de la universalidad se hace evidente entonces, en que no existe tal universalidad, esta representa solo el enfoque o postura ganador de cierta ideología que pretende imponerse, así, el mayor triunfo de los derechos humanos occidentalizados es que su postura se asume como el "ideal", como la "meta última" de los derechos, en suma, como el lugar común que se asume como "dado", el único que debe universalizarse. Lo que esconde la mentira de la universalidad es entonces su propia raíz. Universalidad significa traducir los derechos en componentes locales, lo que lleva inevitablemente a una exclusión de lo ajeno, de lo diferente, y con ello, de todo lo que no esté definido en los términos de la ideología dominante,

Por otro lado, la clasificación en generaciones encubre e imposibilita observar que los derechos humanos poseen un origen de clase, así como de lucha y protesta para poder materializarse. $\mathrm{Si}$ bien los llamados derechos de primera y segunda generación surgen como una petición al poder instituido, esta concepción termina reduciendo a los derechos a un nacimiento casi accidental, el cual viene acompañado de textos que apuntalan en el imaginario colectivo su eficacia, de ahí que terminen, casi inconscientemente, ocultando la lucha necesaria para adquirirlos, así como el componente simbólico que los dotan de contenido.
En el mismo sentido, la clasificación de generaciones no solo da por hecho la existencia de ciertos derechos por "descubrir" en la forma de generaciones, sino que tácitamente reduce estos a una dinámica jerarquizada que facilita para el poder instituido su materialización por "segmentos" es decir, le facilita violentar ciertos derechos, garantizar a medias algunos y de plano, restringir otros, todo ello al amparo de generaciones, que posibilita que, por ejemplo, los derechos de tercera generación pueden ser alcanzados, solo si existe un acuerdo y esfuerzo mundial para ello, lo que de entrada se antoja imposible.

Por lo anterior, considero que, a la luz de los retos actuales en materia de derechos humanos, es momento de transitar a una concepción de escuelas de derechos, la cual se muestra mejor construida y más completa, más precisa y sobre todo realista a la hora de dar respuesta a los retos de los derechos humanos en la actualidad. Así, se debe abandonar la concepción de generaciones de derechos y adoptar y promover una visión fundamentada en las escuelas de derechos humanos. 


\section{Referencias}

Abramovich, V. y Courtis, C. (2001). Los derechos sociales como derechos exigibles. Madrid: Trotta.

Agencia de la ONU para los Refugiados (ACNUR). (2018). ¿Cuáles son los derechos humanos de tercera generación? Consultado el 5 de septiembre de 2018, sitio web: https:// eacnur.org/blog/derechos-humanos-tercera-generacion/

Algan, B. (2004). Rethinking "third generation" human rights. Ankara Law Review. 1, (1), pp. 121-155.

Arias A., Muro V., Buganza J. et. al. (2015, enerojunio). Tesis sobre una teoría crítica de los derechos humanos. Open Insight, VI, pp. 11-34.

Beuchot, M. y Saldaña, J. (2000). Derechos humanos y naturaleza humana. México: UNAM.

Dembour, M. (2006). Who Believes in Human Rights? Reflections on the European Convention. International Journal of Law in Context. 3(4): 338-386.

Derrida, J. (2001). On cosmopolitanism and forgiveness. London: Routledge.

Douzinas, C. (2006). El final de los derechos humanos. Anuario de Derechos Humanos, Nueva Época, Vol. 7. T. 1, pp. 309-340.

Engle, Sally. (2006). Human rights and gender violence: translating international law into local justice. Chicago: The University of Chicago Press.

Gómez, I. (2003). El derecho al desarrollo: entre la justicia y la solidaridad. Cuadernos Deusto de Derechos Humanos, (1). España: Universidad de Deusto.

Gutiérrez, R. (2014). La justiciabilidad de los derechos económicos, sociales, culturales y ambientales en México en el marco de las recientes reformas constitucionales en materia de derechos humanos. En Cervantes, M., Emanuelli, Gómez, O., y Sandoval, A. (coord.). ¿Hay justicia para los derechos económicos, sociales y culturales? Debate abierto a propósito de la reforma constitucional en materia de derechos humanos. México: Instituto de Investigaciones Jurídicas UNAM.

Habermas, J. (2010). La idea de dignidad humana y la utopía realista de los derechos humanos. Anales de la Cátedra Francisco Suárez. 44, pp. 105-121

Jensen, S. (2015, 15 de noviembre). Putting to rest the three generations theory of human rights. Open Global Rights. Recuperado de: https://www.openglobalrights.org/puttingto-rest-the-three-generations-theory-ofhuman-rights/?lang=English

Mutua, M. (2002). Human rights: a political and cultural critique. Univesity of Pennsylvania Press: Philadelphia.

Rabossi, E. (1997). Las generaciones de derechos humanos: la teoría y el cliché. Lecciones y Ensayos. (69-71), p. 41-52.

Scott, R. (2004). Derechos y honra públicos: Louis Martinet, Plessy contra Ferguson y el acceso a la ley en Luisiana, 1888-1917. Debate y Perspectivas, (4), pp. 171-197.

Vasak, K. (noviembre, 1977). A 30-year struggle. The sustained efforts to give force of law to the universal declaration of human rights. The Unesco Courier. (10), p. 29-32. Recuperado de: http://unesdoc. unesco.org/images/0007/000748/074816eo. pdf\#nameddest $=48063$

Žižek, S. (2007). Robespierre: virtud y terror. Madrid: Akal.

Žižek, S. (2008). En defensa de la intolerancia. Madrid: Ediciones Sequitur. 